\title{
ANALISIS FAKTOR YANG MEMPENGARUHI PEMBERIAN IMUNISASI Hb-0 DI WILAYAH KERJA PUSKESMAS BATANG BULU KECAMATAN BARUMUN SELATAN KABUPATEN PADANG LAWAS
}

\author{
Kumala Sari Rambe \\ Akbid Baruna Husada Sibuhuan
}

\begin{abstract}
Abstrak
Menurut WHO (Word Health Organization), lebih dari 350 juta orang di dunia terinfeksi Hepatitis B, untuk menurunkan angka kesakitan dan kematian akibat penyakit $\mathrm{Hb}$ sejak dini, maka WHO telah merekomendasikan program immunisasi $\mathrm{Hb}$ untuk semua bayi (Universal Chilhood Immunization Against $\mathrm{Hb}$ ). Penelitian ini dilakukan untuk mengetahui faktor yang mempengaruhi pemberian immunisasi $\mathrm{Hb}-0 \mathrm{di}$ Wilayah Kerja Puskesmas Batang Bulu Kecamatan Barumun Selatan Kabupaten Padang Lawas. Rancangan penelitian ini menggunakan kasus kontrol (case control) dengan jumlah sampel kasus 40 responden dan jumlah kontrol 40 responden. Variabel dependen penelitian ini adalah umur ibu, pendidikan, pengetahuan, sikap, kepercayaan/tradisi, dukungan suami, jarak, penolong persalinan, kunjungan antenatal. Hasil penelitian menunjukkan bahwa faktor yang paling dominan mempengaruhi pemberian imunisasi $\mathrm{Hb}-0$ adalah kepercayaan/tradisi $(\mathrm{p}=0,019)$ dan penolong persalinan $(\mathrm{p}=0,021)$. Bidan lebih meningkatkan pelayanan kesehatan dan penyuluhan kepada masyarakat khususnya ibu hamil tentang imunisasi $\mathrm{Hb}-0$ pada bayi 0-7 hari.
\end{abstract}

Kata Kunci : Immunisasi Hepatitis B 0

\section{PENDAHULUAN}

Imunisasi merupakan salah satu upaya pelayanan kesehatan dasar dari segi preventif yang memegang peranan dalam menurunkan angka kematian bayi. Upaya pelayanan imunisasi dilakukan melalui kegiatan imunisasi rutin dan tambahan dengan tujuan untuk menurunkan angka kesakitan dan kematian akibat Penyakit-Penyakit Dapat Dicegah Dengan Imunisasi (PD3I).

WHO (World Health Organization), lebih dari 350 juta orang di dunia terinfeksi hepatitis. untuk menurunkan angka kesakitan dan kematian akibat penyakit hepatitis b sejak dini, maka $\mathrm{WHO}$ telah merekomendasikan program imunisasi hepatitis B untuk semua bayi (Universal Childhood Imunisasi Against $\mathrm{Hb}$ ). Infeksi pada anak umumnya asimtomatis tetapi 80-95\% akan menjadi kronis dan dalam 10-20 tahun akan menjadi sirosis atau Karsinoma hepatoseluler (KHS).

Angka Kematian Bayi (AKB) di Indonesia masih cukup tinggi dibandingkan dengan negara ASEAN lainnya. Menurut data Survei Demografi Kesehatan Indonesia (SDKI) tahun 2012, AKB 32 per 1000 kelahiran hidup, Angka Kematian Neonatus (AKN) 19 per 1000 kelahiran hidup. Berdasarkan kesepakatan global (Millenium Develoment Goals/MDG's 2000) pada tahun 2015.

Cakupan imunisasi di Sumatera Utara secara umum cukup tinggi, tetapi tidak merata setiap kabupaten, ada di antaranya di bawah 80 persen.
Sedangkan infeksi hepatitis pada bayi dan balita menyebabkan terjadinya infeksi kronis yang dapat menimbulkan cirrhosis hepatis dan kanker hati pada saat dia dewasa, sehingga bila cakupan imunisasinya rendah, hal ini juga berpotensi untuk menimbulkan KLB di kemudian hari.

Berdasarkan Laporan Pelayanan Kesehatan Dinas Kesehatan Kabupaten Padang Lawas periode Januari s/d Agustus 2015, jumlah sasaran bayi sebanyak 192 terdiri dari Laki-laki 95 bayi dan perempuan 97 bayi dan jumlah bayi yang mendapat imunisasi Hb-0 sebanyak 35 orang bayi terdiri dari 18 bayi perempuan dan 17 bayi laki-laki sebesar 18,23\% dan angka ini menunjukkan bahwa pencapaian kabupaten belum sesuai dengan target nasional. Puskesmas Batang Bulu terletak di Kecamatan Barumun selatan terdiri atas 11 desa dengan jumlah bidan desa sebanyak 11 .

Tujuan penelitian ini adalah untuk mengetahui faktor yang mempengaruhi pemberian imunisasi Hepatitis B 0 di wilayah kerja Puskesmas Batang Bulu Kecamatan Barumun Selatan Kabupaten Padang Lawas.

\section{METODE PENELITIAN}

Rancangan penelitian ini adalah studi case control yaitu untuk mengetahui analisis faktor yang mempengaruhi pemberian imunisasi $\mathrm{Hb}-0$. Penelitian 
ini dimulai dengan mengidentifikasi populasi kasus adalah ibu yang mempunyai bayi 0-7 hari yang tidak mendapatkan imunisasi $\mathrm{Hb}-0$, dan populasi kontrol adalah ibu yang mempunyai bayi $0-12$ bulan yang mendapatkan imunisasi Hb-0. Besar sampel kasus pada penelitian ini sebesar 40 responden dan sampel kontrol sebesar 40 responden. Lokasi penelitian di wilayah kerja Puskesmas Batang Bulu Kecamatan Barumun Selatan Kabupaten Padang Lawas dan waktu penelitian mulai bulan Agustus s/d Oktober 2015. Cara pengambilan sampel dengan teknik purposive sampling.

\section{HASIL PENELITIAN}

Berdasarkan hasil penelitian yang dilakukan oleh peneliti dapat dilihat pada .Distribusi Frekuensi Faktor Predisposisi, Pendukung dan Pendorong Pada Kelompok Kasus dan Kelompok Kontrol di wilayah Kerja Puskesmas Batang Bulu Kabupaten Padang Lawas

\begin{tabular}{|c|c|c|c|c|}
\hline \multirow{2}{*}{$\begin{array}{c}\text { Faktor } \\
\text { Predisposisi, } \\
\text { Pendukung, } \\
\text { Pendorong }\end{array}$} & \multicolumn{2}{|c|}{ Kasus } & \multicolumn{2}{|c|}{ Kontrol } \\
\hline & $\mathrm{F}$ & $\%$ & $\mathrm{~F}$ & $\%$ \\
\hline \multicolumn{5}{|l|}{ Umur } \\
\hline $\begin{array}{l}<20 \text { dan }>35 \\
\text { tahun }\end{array}$ & 21 & 52,5 & 14 & 35 \\
\hline 20-35 tahun & 19 & 47,5 & 26 & 65 \\
\hline \multicolumn{5}{|l|}{ Pekerjaan } \\
\hline IRT & 28 & 70 & 24 & 60 \\
\hline PNS dan Petani & 12 & 30 & 16 & 20 \\
\hline \multicolumn{5}{|l|}{ Pendidikan } \\
\hline Rendah (SMP,SD) & 25 & 62,5 & 13 & 32,5 \\
\hline Tinggi & 15 & 37,5 & 27 & 67,5 \\
\hline \multicolumn{5}{|l|}{ (SMA,Diploma/P } \\
\hline \multicolumn{5}{|l|}{ T) } \\
\hline \multicolumn{5}{|l|}{ Pengetahuan } \\
\hline Kurang & 23 & 57,5 & 13 & 32,5 \\
\hline Baik & 17 & 42,5 & 27 & 67,5 \\
\hline \multicolumn{5}{|l|}{ Sikap } \\
\hline Kurang & 20 & 50 & 18 & 45 \\
\hline Baik & 20 & 50 & 22 & 55 \\
\hline \multicolumn{5}{|c|}{ Kepercayaan/tradisi } \\
\hline Ada & 22 & 55 & 11 & 27,5 \\
\hline Tidak Ada & 18 & 45 & 29 & 72,5 \\
\hline \multicolumn{5}{|l|}{ Dukungan Suami } \\
\hline Tidak Mendukung & 22 & 55 & 11 & 27,5 \\
\hline Mendukung & 18 & 45 & 29 & 72,5 \\
\hline \multicolumn{5}{|l|}{ Jarak } \\
\hline Jauh & 20 & 50 & 20 & 50 \\
\hline Dekat & 20 & 50 & 20 & 50 \\
\hline \multicolumn{5}{|l|}{ Penolong Persalinan } \\
\hline Non Nakes & 24 & 60 & 13 & 32,5 \\
\hline Nakes & 16 & 40 & 27 & 67,5 \\
\hline \multicolumn{5}{|c|}{ Kunjungan antenatal } \\
\hline Tidak Ada & 18 & 45 & 20 & 50 \\
\hline Ada & 22 & 55 & 20 & 50 \\
\hline
\end{tabular}

Berdasarkan tabel di atas dapat dilihat bahwa umur responden pada kelompok kasus mayoritas dengan umur $<20$ dan $>35$ Tahun sebanyak 21 orang $(52,5 \%)$ dan pada kelompok kontrol Mayoritas dengan umur 20-35 Tahun sebanyak 26 Responden (65\%).

Pekerjaan responden pada kelompok kasus mayoritas dengan pekerjaan IRT sebanyak 28 orang (70\%) dan pada kelompok kontrol terdapat bahwa dengan pekerjaan IRT sebanyak 24 responden (60\%).

Pendidikan responden pada kelompok kasus mayoritas dengan pendidikan rendah (SMP,SD) sebanyak 25 reseponden $(62,5 \%)$, dan pada kelompok kontrol mayoritas dengan pendidikan tinggi (SMA,Diploma/PT) sebanyak 27 responden $(67,5 \%)$.

Pengetahuan responden pada kelompok Kasus mayoritas dengan pengetahuan kurang sebanyak 23 responden $(57,5 \%)$ dan pada kelompok kontrol mayoritas dengan pengetahuan baik sebanyak 27 responden $(67,5 \%)$.

Sikap responden pada kelompok kasus dengan sikap kurang sebanyak 20 responden (50\%) dan pada kelompok kontrol mayoritas dengan sikap baik sebanyak 22 responden $(55 \%)$.

Kepercayaan/tradisi pada kelompok kasus mayoritas dengan kepercayaan/tradisi ada sebanyak 22 responden $(55 \%)$ dan pada kelompok kontrol mayoritas dengan kepercayaan/tradisi tidak ada sebanyak 29 responden $(72,5 \%)$.

Kepercayaan/ tradisi erat kaitannya dengan nilai budaya, begitu pula kepercayaan/tradisi yang dianut oleh sebagian masyarakat yang sudah melekat sangat sulit untuk diubah, misalnya ibu-ibu tidak mau memberikan imunisasi Hepatitis B-0 pada bayi 0-7 hari karena mereka tidak mau membawa bayinya keluar rumah sebelum berusai 40 hari.

Dukungan suami responden pada kelompok kasus mayoritas dengan tidak mendukung sebanyak 22 responden $(55 \%)$ dan pada kelompok kontrol mayoritas dengan mendukung sebanyak 29 responden $(72,5 \%)$.

Jarak ke fasilitas kesehatan pada kelompok kasus dengan jarak jauh sebanyak 20 responden (50\%) dan pada kelompok kontrol dengan jarak jauh sebanyak 20 responden $(50 \%)$.

Penolong persalinan pada kelompok kasus mayoritas dengan non nakes sebanyak 24 responden $(60 \%)$ dan pada kelompok kontrol dengan nakes sebanyak 27 responden $(67,5 \%)$.

Kunjungan antenatal pada kelompok kasus mayoritas dengan kunjungan antenatal ada sebanyak 22 responden $(55 \%)$ dan pada kelompok kontrol dengan kunjungan antenatal tidak ada sebanyak 20 responden $(50 \%)$.

Pengaruh Faktor Predisposisi, Pendorong dan Pendukung dengan Pemberian Imunisasi $\mathrm{Hb}-\mathrm{O}$ di Wilayah Kerja Puskesmas Batang Bulu Kabupaten Padang Lawas. 


\begin{tabular}{|c|c|c|c|c|c|c|}
\hline \multirow{3}{*}{$\begin{array}{c}\text { Faktor } \\
\text { Predisposisi, } \\
\text { Pendukung, } \\
\text { Pendorong }\end{array}$} & \multicolumn{4}{|c|}{$\begin{array}{c}\text { Pemberian Imunisasi } \\
\text { Hb- } 0\end{array}$} & \multirow[t]{3}{*}{$\begin{array}{c}P \\
\text { Value }\end{array}$} & \multirow[t]{3}{*}{ OR $95 \% \mathrm{Cl}$} \\
\hline & \multicolumn{2}{|c|}{ Kasus } & \multicolumn{2}{|c|}{ Kontrol } & & \\
\hline & $\mathrm{F}$ & $\%$ & $\mathrm{~F}$ & $\%$ & & \\
\hline \multicolumn{7}{|l|}{ Umur } \\
\hline $\begin{array}{l}<20 \text { dan }>35 \\
\text { tahun }\end{array}$ & 21 & 52,5 & 14 & 35 & 0,115 & $\begin{array}{c}2,053 \\
0,836-5,041\end{array}$ \\
\hline 20-35 tahun & 19 & 47,5 & 26 & 65 & & \\
\hline \multicolumn{7}{|l|}{ Pekerjaan } \\
\hline IRT & 28 & 70 & 24 & 60 & 0,348 & 1,556 \\
\hline $\begin{array}{l}\text { PNS dan } \\
\text { Petani }\end{array}$ & 12 & 30 & 16 & 40 & & $\begin{array}{c}0,616- \\
3,927\end{array}$ \\
\hline \multicolumn{7}{|l|}{ Pendidikan } \\
\hline $\begin{array}{l}\text { Rendah } \\
\text { (SMP,SD) }\end{array}$ & 25 & 62,5 & 13 & 32,5 & 0,007 & $\begin{array}{c}3,462 \\
1,379-\end{array}$ \\
\hline $\begin{array}{l}\text { Tinggi } \\
\text { (SMA,Diplo } \\
\text { ma/PT) }\end{array}$ & 15 & 37,5 & 27 & 67,5 & & 8,691 \\
\hline \multicolumn{7}{|l|}{ Pengetahuan } \\
\hline Kurang & 23 & 57,5 & 13 & 32,5 & 0,025 & 2,810 \\
\hline Baik & 17 & 42,5 & 27 & 67,5 & & $\begin{array}{c}1,129- \\
6,991\end{array}$ \\
\hline \multicolumn{7}{|l|}{ Sikap } \\
\hline Kurang & 20 & 50 & 18 & 45 & 0,654 & 1,222 \\
\hline Baik & 20 & 50 & 22 & 55 & & $\begin{array}{c}0,508- \\
2,943\end{array}$ \\
\hline \multicolumn{7}{|c|}{ Kepercayaan/tradisi } \\
\hline Ada & 22 & 55 & 11 & 27,5 & 0,012 & 3,222 \\
\hline Tidak ada & 18 & 45 & 29 & 72,5 & & $\begin{array}{c}1,268- \\
8,188\end{array}$ \\
\hline \multicolumn{7}{|c|}{ Dukungan Suami } \\
\hline $\begin{array}{l}\text { Tidak } \\
\text { Mendukung }\end{array}$ & 22 & 55 & 11 & 27,5 & 0,012 & $\begin{array}{c}3,222 \\
01,268-\end{array}$ \\
\hline Mendukung & 18 & 45 & 29 & 72,5 & & 8,188 \\
\hline Jarak & & & & & & \\
\hline Jauh & 20 & 50 & 20 & 50 & 1,000 & 1,000 \\
\hline Dekat & 20 & 50 & 20 & 50 & & $\begin{array}{c}0,416- \\
2,403\end{array}$ \\
\hline \multicolumn{7}{|c|}{ Penolong Persalinan } \\
\hline $\begin{array}{l}\text { Non tenaga } \\
\text { Kesehatan }\end{array}$ & 24 & 60 & 13 & 32,5 & 0,014 & $\begin{array}{c}3,115 \\
1,247-\end{array}$ \\
\hline $\begin{array}{l}\text { Tenaga } \\
\text { Kesehatan }\end{array}$ & 16 & 40 & 27 & 67,5 & & 7,781 \\
\hline \multicolumn{7}{|c|}{ Kunjungan Antenatal } \\
\hline Ada & 18 & 45 & 20 & 50 & 0,654 & 0,818 \\
\hline Tidak ada & 22 & 55 & 20 & 50 & & $\begin{array}{c}0,340- \\
1,970\end{array}$ \\
\hline
\end{tabular}

Dari hasil uji statistik dengan menggunakan Chi Square menunjukkan bahwa tidak ada pengaruh yang signifikan antara umur dengan pemberian imunisasi Hb-0 ( $\mathrm{p}=0,115)$.

Ada pengaruh yang signifikan antara pekerjaan dengan pemberian imunisasi $\mathrm{Hb}-0$ ( $\mathrm{p}=$ $0,348)$

Ada pengaruh yang signifikan antara pendidikan dengan pemberian imunisasi $\mathrm{Hb}-0(\mathrm{p}=$ 0,007). Dengan nilai $(\mathrm{OR})=3,462($ OR $95 \% C I$ $=1,379-8,691$ ), menunjukkan bahwa bayi yang tidak diberikan imunisasi $\mathrm{Hb}-0 \quad 3.46$ kali pemberian kemungkinan mempunyai risiko ibu dengan pendidikan rendah dibandingkan dengan bayi yang mendapatkan imunisasi $\mathrm{Hb}-0$.

Ada pengaruh yang signifikan antara pengetahuan dengan pemberian imunisasi $\mathrm{Hb}-0(\mathrm{p}=$
0,025). Dengan nilai $(\mathrm{OR})=2,810($ OR $95 \% C I=$ $1,129-6,991)$, menunjukkan bayi yang tidak diberikan imunisasi $\mathrm{Hb}-0$ 2.8 kali lebih besar pemberian kemungkinan mempunyai pengetahuan kurang dibandingkan dengan bayi yang mendapat imunisasi $\mathrm{Hb}-0$.

Tidak ada pengaruh yang signifikan antara sikap dengan pemberian imunisasi $\mathrm{Hb}-0(\mathrm{p}=0,654)$.

Ada pengaruh yang signifikan antara kepercayaan/tradisi dengan pemberian imunisasi $\mathrm{Hb}-0$ $(\mathrm{p}=0,012)$. Dengan nilai $(\mathrm{OR})=3,222($ OR $95 \% C I$ $=1,268-8,188$ ), menunjukkan bahwa bayi yang tidak diberikan imunisasi $\mathrm{Hb}-0 \quad 3.2$ kali pemberian kemungkinan mempunyai risiko ibu dengan kepercayaan/tradisi ada dibandingkan dengan bayi yang diberikan imunisasi $\mathrm{Hb}-0$.

Ada pengaruh yang signifikan antara dukungan suami dengan pemberian imunisasi $\mathrm{Hb}-0$ ( $\mathrm{p}$ $=0,012)$. Dengan nilai $(\mathrm{OR})=3.222($ OR $95 \% C I$ $=1,268-8,188$ ), menunjukkan bahwa bayi yang tidak diberikan imunisasi $\mathrm{Hb}-0 \quad 3.2$ kali pemberian kemungkinan mempunyai risiko ibu dengan tidak adanya dukungan suami dibandingkan dengan bayi yang mendapat imunisasi $\mathrm{Hb}-0$.

Tidak ada pengaruh yang signifikan antara jarak dengan pemberian imunisasi $\mathrm{Hb}-0(\mathrm{p}=1,000)$.

Ada pengaruh yang signifikan antara penolong persalinan dengan pemberian imunisasi $\mathrm{Hb}-0$ ( $\mathrm{p}=$ 0,014). Dengan nilai $(\mathrm{OR})=3,115($ OR $95 \% \mathrm{CI}$ $=1,247-7,781$ ), menunjukkan bahwa bayi yang tidak diberikan imunisasi $\mathrm{Hb}-0 \quad 3.1$ kali pemberian kemungkinan mempunyai risiko ibu dengan penolong persalinan yang ditolong oleh non tenaga kesehatan dibandingkan dengan bayi yang mendapat imunisasi $\mathrm{Hb}-0$.

Tidak ada pengaruh yang signifikan antara kunjungan antenatal dengan pemberian imunisasi $\mathrm{Hb}-0$ $(\mathrm{p}=0,654)$.

Analisis Multivariat Pengaruh Faktor Predisposisi, Pendukung, Pendorong dengan Pemberian Imunisasi Hb-0 di Wilayah Kerja Puskesmas Batang Bulu Kabupaten Padang Lawas

\begin{tabular}{|c|c|c|c|c|c|c|c|}
\hline \multirow[t]{2}{*}{ No. } & \multirow{2}{*}{$\begin{array}{c}\text { Variabel } \\
\text { Penelitian }\end{array}$} & \multirow[t]{2}{*}{ B } & \multirow[t]{2}{*}{ S.E. } & \multirow[t]{2}{*}{ Sig } & \multirow[t]{2}{*}{ OR } & \multicolumn{2}{|c|}{$\begin{array}{c}\text { 95\% C.I.for } \\
\operatorname{Exp}(B)\end{array}$} \\
\hline & & & & & & Lower & Upper \\
\hline \multicolumn{8}{|c|}{ Faktor Predisposisi: } \\
\hline & $\begin{array}{l}\text { Kepercaya } \\
\text { an/tradisi }\end{array}$ & 1.155 & .494 & .019 & 3.175 & 1.206 & 8.357 \\
\hline \multicolumn{8}{|c|}{ Faktor Pendorong: } \\
\hline 2. & $\begin{array}{l}\text { Penolong } \\
\text { Persalinan }\end{array}$ & 1.122 & .485 & .021 & 3.070 & 1.186 & 7.947 \\
\hline & onstant & -1.290 & .475 & .007 & .275 & & \\
\hline
\end{tabular}

Berdasarkan Tabel di atas, dapat dilihat bahwa seluruh sub variabel penelitian telah signifikan. Variabel-variabel tersebut adalah variabel faktor predisposisi yaitu kepercayaan/tradisi ( $p=0,019$; OR = 3.175), dan faktor pendorong yaitu penolong persalinan $(\mathrm{p}=0,021 ; \mathrm{OR}=3.070)$. Dari data tersebut maka variabel yang paling dominan berpengaruh dengan 
pemberian imunisasi $\mathrm{Hb}-0$ adalah variabel kepercayaan/tradisi $(\mathrm{p}=0,19 ; \quad \mathrm{OR}=3.175)$ menunjukkan bahwa bayi yang tidak di imunisasi Hb-0 3.2 kali pemberian kemungkinan mempunyai risiko dengan ibu yang mempunyai kepercayaan/tradisi dibandingkan bayi yang mendapat imunisasi $\mathrm{Hb}-0$.

\section{PEMBAHASAN}

\section{Umur ibu dengan pemberian Imunisasi Hb-0}

Umur dapat mempengaruhi cara pandang seseorang dalam menghadapi berbagai hal ataupun dalam mengambil keputusan. Proses perkembangan kedewasaan di tentukan dengan bertambahnya usia. Umur merupakan salah satu faktor pemudah yang berguna untuk melakukan suatu tindakan yang mendukung kesehatan dalam hal ini adalah pemebrian imunisasi $\mathrm{Hb}$ pada bayi 0-7 hari. Penelitian ini didukung oleh penelitian yang dilaukan Azmi (2005) di Puskesmas Biha Lampung, yang menyatakan tidak ada hubungan yang bermakna antara umur ibu dengan pemberian imunisasi $\mathrm{Hb}$ pada bayi 0-7 hari.

\section{Pekerjaan dengan pemberian Imunisasi Hb-0}

Secara teori pekerjaan ibu akan mempengaruhi perilaku ibu melengkapi imunisasi anak. Ibu yang bekerja akan lebih sibuk sehingga tidak ada waktu untuk melengkapi status imunisasi anaknya. Sebaliknya ibu yang tidak bekerja mempunyai banyak waktu untuk dapat mengimunisasi anaknya (Hastono, 2009). Pekerjaan merupakan salah satu hal yang mempengaruhi pertumbuhan dan perkembangan seorang anak karena hal ini berkaitan dengan status ekonomi dari keluarga orang tua dapat menyediakan semua kebutuhan anak baik kebutuhan primer maupun kebutuhan sekunder. Hasil ini didukung oleh penelitian oleh Suandi (2005) di Kecamatan Talaga Majalengka, yang menyebutkan bahwa tidak terdapat hubungan yang bermakna antara pekerjaan ibu untuk mendapatkan imunisasi $\mathrm{Hb}$ sedini mungkin.

\section{Pendidikan dengan pemberian imunisasi HB-0}

Tingkat pendidikan akan sangat berpengaruh terhadap perubahan sikap dan perilaku hidup sehat. Tingkat pendidikan yang lebih tinggi akan memudahkan seseorang atau masyarakat untuk lebih mudah menerima informasi dan mengimplementasikannya dalam perilaku dan gaya hidup sehari-hari, khususnya dalam hal kesehatan. Tingkat pendidikan inu akan mempengaruhi derajat kesehatan (Sasmita, 2006). Hasil ini sejalan dengan penelitian yang dilakukan oleh Arwin (2011) di Kota Solok, yang menyatakan bahwa tingkat pendidikan berhubungan dengan pemberian imunisasi $\mathrm{Hb}$ pada bayi 0-7 hari.

\section{Pengetahuan dengan Pemberian Imunisasi Hb-0}

Hasil ini sesuai dengan penelitian sebelumnya yang dilakukan oleh Umar (2008) di Puskesmas Gunungpati, yang menyatakan bahwa ada hubungan antara pengetahuan ibu dengan kelengkapan imunisasi Bayi $\mathrm{p}=0,001(\mathrm{p}<0,05)$. Sejalan dengan hasil penelitian (Notoatmodjo, 2007) Pengetahuan adalah dari hasil tahu dan ini terjadi setelah orang melakukan penginderaan terhadap suatu objek tertentu yang mana penginderaan ini terjadi melalui panca indera manusia yakni indera penglihatan, pendengaran, penciuman, rasa, dan raba yang sebagian besar pengetahuan manusia diperoleh melalui mata dan telinga.

\section{Sikap dengan Pemberian Imunisasi Hb-0}

Menurut Wawan (2010) adalah predisosisi untuk melakukan atau tidak melakukan suatu perilaku tertentu, sehingga sikap bukan hanya kondisi internal psikologis yang murni dari individu, tetapi lebih merupakan proses kesadaran yang bersifat individual dalam arti proses ini terjadi secara subjektif dan unik pada diri seseorang. Sikap adalah suatu bentuk evaluasi atau reaksi perasaan. Sikap terbentuk dari adanya interaksi sosial yang dialami oleh individu. Sikap menggambarkan perilaku suka atau tidak suka seseorang terhadap obyek. Faktor-faktor yang mempengaruhi pembentukan sikap adalah pengalaman pribadi, kebudayaan, orang lain yang dianggap penting, media massa, institusi atau lembaga pendidikan dan lembaga agama serta faktor emosi dalam individu (Azwar, 2009). Sikap juga berpengaruh dalam pemberian imunisasi $\mathrm{Hb}-0$.

\section{Kepercayaan/ Tradisi dengan Pemberian Imunisasi Hb-0}

Kepercayaan/ tradisi erat kaitannya dengan nilai budaya, begitu pula kepercayaan/tradisi yang dianut oleh sebagian masyarakat yang sudah melekat sangat sulit untuk diubah, misalnya ibu-ibu tidak mau memberikan imunisasi $\mathrm{Hb}-0$ pada bayi 0-7 hari karena mereka tidak mau membawa bayinya keluar rumah sebelum berusai 40 hari. Hali ini sulit untuk diubah karena ibu-ibu merasa khawatir kalau membawa keluar rumah sebelum 40 hari bayinya akan terkena penyakit yang akan susah untuk disembuhkan, selain itu ada bebrapa desa yang mempunyai kebudayaan pantang besi sehingga bayi yang baru lahir tidak boleh untuk di imunisasi.

Tradisi keluarga adalah kebiasaan keluarga untuk membawa bayinya untuk mendapatkan imunisasi $\mathrm{Hb}-0$ karena dengan tidak adanya tradisi maka besar kemungkinan bayi tidak mendapat imunisasi $\mathrm{Hb}-0$, dan yang sebaliknya apabila dalam keluarga tersebut mempunyai tradisi maka besar kemungkinan bayi tersebut mendapatkan imunisasi $\mathrm{Hb}-0$.

Dukungan suami dengan Pemebrian Imunisasi Hb-0

Menurut Notoadmodjo (2010) mengatakan bahwa salah satu penyebab perubahan perilaku kesehatan seseorang dapat ditentukan oleh ada tidaknya dukungan sosial (Social Support) dari lingkungan sekitar. Dalam hal ini termasuk juga dukungan suami dalam pemberian imunisasi $\mathrm{Hb}$ pada bayi 0-7 hari. Dukungan dari orang terdekat (suami) merupakan motivasi untuk ibu melakukan keputusan mengimunisasi bayinya, dengan adanya dukungan dari suami, ibu akan merasa sangat dihargai dan diperhatikan karena dengan adanya dukungan tersebut 
membuat ibu merasa suami ikut bertanggung jawab dan ikut memperhatikan dalam hal kesehatan bagi bayi mereka.

\section{Jarak kefasilitas kesehatan dengan pemberian imunsiasi Hb-0}

Jarak adalah lama tempuh ibu untuk memperoleh pelayanan baik itu berjalan kaki maupun berkenderaan ke pelayanan kesehatan khususnya untuk mendapatkan imunisasi $\mathrm{Hb}-0$. Semakin jauh jarak rumah ibu ke pelayanan kesehatan semakin besar kemungkinan ibu untuk tidak membawa bayinya kepelayanan kesehatan, sebaliknya semakin dekat jarak ibu kepelayanan kesehatan semakin besar pula kemungkinan untuk ibu membawa bayinya ke pelayanan kesehatan untuk mendapatkan HB-0.

Hanum (2005), menyebutkan bahwa jarak dari tempat tinggal ke tempat pelayanan imunisasi memiliki hubungan yang bermakna dengan kelengkapan imunisasi. Selain jarak, kemudahan transportasi menuju ke tempat pelayanan imunisasi juga berpengaruh. Walaupun jarak dari tempat tinggal ke tempat pelayanan imunisasi jauh, namun jika dapat dijangkau dengan mudah maka imunisasi tetap dapat dilakukan.

\section{Penolong Persalinan dengan Pemberian Imunisasi HB- 0}

Tenaga yang dapat memberikan pertolongan persalinan dapat dibedakan menjadi 2 yaitu tenaga kesehatan (Dokter Obgyn, Dokter Umum, Bidan dan perawat) dan tenaga Non Kesehatan (Dukun bayi terlatih/tidak terlatih dan keluarga).

Pemilihan ibu hamil yang ingin bersalin pada bidan umumnya merupakan masyarakat yang sulit memperoleh akses kepelyanan kesehatan (praktik Bidan), sehingga membutuhkan waktu lama dibandingkan mendapatkan pertolongan persalinan oleh dukun bayi yang sangat mudah dan murah.

\section{Kunjungan Antenatal dengan pemberian imunisasi Hb-0}

Antenatal Care (ANC) adalah suatu pemeriksaan dan asuhan kepada ibu hamil mulai konsepsi yang ditandai dengan haid terlambat sampai dengan proses persalinan. Dengan antenatal care yang teratur diharapkan kondisi ibu dan janin tetap dalam kondisi yang optimal baik dalam kehamilan sampai dengan proses persalinan. Selain ANC yang teratur diharapkan ibu mendapatkan informasi yang lengkap tentang imunisasi $\mathrm{Hb}$. Dengan demikian pada saat melahirkan bayinya nanti, ibu telah siap untuk mengimunisasi bayinya.

Hasil ini sejalan dengan penelitian Suandi (2005), yang menyatakan bahwa ibu yang kunjungan antenatal tidak ada berisiko 3,45 kali tidak diberikan imunisasi Hepatitis b pada bayi 0-7 hari dibandingkan dengan kunjungan antenatal ada.

\section{KESIMPULAN}

Berdasarkan hasil penelitian dan pembahasan dapat diambil beberapa kesimpulan sebagai berikut :
Kepercayaan/Tradisi berpengaruh terhadap pemberian imunisasi $\mathrm{Hb}-0$. Bayi yang tidak diberikan imunisasi $\mathrm{Hb}-0 \quad 3.2$ kali pemberian kemungkinan mempunyai risiko Ibu yang mempunyai kepercayaan/tradisi ada dibandingkan dengan bayi yang diberikan imunisasi.

Penolong persalinan berpengaruh terhadap pemberian imunisasi Hb-0. Bayi yang tidak diberikan imunisasi $\mathrm{Hb}-0$ 3.1 kali pemberian kemungkinan mempunyai risiko Ibu yang ditolong oleh non tenaga kesehatan dibandingkan bayi yang diberikan imunisasi $\mathrm{Hb}$ 0 .

\section{SARAN}

Tenaga kesehatan terutama bidan agar lebih meningkatkan pelayanan kesehatan dan melakukan penyuluhan kepada masyarakat khususnya ibu hamil tentang pemberian imunisasi HB-0 pada bayi usia 0-7 hari agar terhindar dari penyakit Hepatitis.

Tokoh adat di Wilayah Kerja Puskesmas Batang Bulu agar memberikan bantuan dan dukungan serta meyakinkan masyarakat bahwa bayi yang baru lahir harus di imunisasi Hb-0 khususnya bayi yang berumur 0-7 hari.

\section{DAFTAR PUSTAKA}

Ambari., 2010. Hubungan Antara dukungan keluarga dengan keberfungsian social pada pasien Skizifrenia pasca perawatan di rumah sakit. Skripsi. UNNES

Anandita, 2010. Mengenal Jenis Imunisasi. Quadra : Bogor

Arwin, P. 2011. Faktor-faktor yang berhubungan dengan praktek ibu mendapatkan imunisasi $\mathrm{Hb}-0$ bayi di Kecamatan Talaga Kabupaten Majalengka Tahun 2011, Depok, FKM UI

Azmi, A 2005. Studi tentang pengetahuan, sikap dan perilaku ibu bayi terhadap pemberian imunisasi hepatitis b-0 pada bayi 0-7 hari di Puskesmas Biha Kecamatan Pesisir Selatan Kabupaten Lampung Tahun 2015, Skripsi Depok, FKM UI.

Depkes RI, 2005. Pedoman teknis imunisasi tingkat puskesmas. Jakarta: Direktorat Jendral PP dan PL.

2009. Modul kegiatan lima imunisasi dasar lengkap: Jakarta.

, 2010. Peningkatan Cakupan dan mutu pelayanan imunisasi di Puskesmas.

Dinas Kesehatan Kabupaten Padang Lawas, 2015. Bidang KIA program imunisasi rekapitulasi laporan cakupan program imunisasi : Sibuhuan

Hanum M., 2010. Tumbuh Kembang, Status Gizi dan Imunisasi Dasar pada Balita., Yogyakarta., Nuha Medika.

Helmiati, 2011. Faktor-faktro yang berhubungan dengan pemberian imunisasi $\mathrm{Hb}-0$ (0-7 hari) pada bayi (011 bulan) di Puskesmas Pasar Kuok Kabupaten Pesisir Selatan Tahun 2011. Skripsi Depok FKM UI 
Isfan, R., 2006. Faktor-faktor yang berhubungan dengan status imunisasi dasar pada anak di Puskesmas Pau Kota Padang Tahun 2006. Tesis

Khatab, N. 2006. Perilaku ibu dalam pemberian imunisasi Hb-0 pada bayi 0-7 hari di Puskesmas Lubuk Alang Kecamatan Lubuk Alang Kabupaten Padang Pariaman tahun 2006. Tesis Depok FKM UI.

Markum AH, 2008. Imunisasi. Edisi kedua.Jakarta:Fakultas Kedokteran Universitas Indonesia.

Maryunani, A. 2011. Ilmu Kesehatan Anak Dalam Kebidanan. Trans Info Media : Jakarta

Muliani., 2013. Hubungan pelayanan imunisasi dengan pemberian imunisasi $\mathrm{Hb}-0$ di Wilayah Puskesmas Ponre Kabupaten Bulukumba

Mulyantoro, A. 2004. Faktor penjelas perbedaan status imunisasi $\mathrm{Hb}-0$ pada bayi 0-7 hari antara Puskesmas Sukarame dan Puskesmas Korpri Kota Bandar Lampung, skripsi, Depok, FKM UI

Muzaham, F., 2005. Sosiologi Kesehatan. Jakarta : Universitas Indonesia

Notoatmodjo, S., 2003. Pendidikan Kesehatan dan Ilmu Perilaku, Jakarta, Rineka Cipta

Proverawati A., Citra Setyo., 2010. Imunisasi dan Vaksinasi., Yogyakarta., Nuha offset

Ranuh, I.G.N. dkk. 2008. Pedoman Imunisasi Di Indonesia. Badan Penerbit Ikatan Dokter Anak Indonesia : Jakarta

Riyanto, A., 2009. Pengolahan dan Analisis Data Kesehatan, Yogyakarta : Nuha Medika.
Rozalina., 2012., Perilaku Ibu dalam pemberian Imunisasi Hb-0 pada bayi 0-7 hari di wilayah kerja Puskesmas Sukamara Kabupaten Sukamara provinsi Kalimantan Tengah Tahun 2012. FKM UI

Saifuddin., 2006., Buku acuan Nasional Pelayanan Kesehatan Maternal dan Neonatal. Jakarta : Bina Pustaka

Saryono, 2008. Metodologi Penelitian Kesehatan, Yogyakarta : Mitra

Suandi, A, 2005. Pengaruh penolong persalinan terhadap kontak pertama imunisasi $\mathrm{Hb}-0$ bayi di Kecamatan Talaga Kabupaten Majalengka Tahun 2005, Tesis, Depok, FKM UI

Supriadi, D. 2002. Hubungan kunjungan neonatal dini dengan status imunisasi $\mathrm{Hb}-0$ sedini mungkin pada bayi yang mendapat Hb-0 di Kabupaten Tasikmalaya Tahun 2011. Tesis

Suyani., Nurfadila., 2010, gambaran pengetahuan tentang imunisasi $\mathrm{Hb}:$ diakses pada tanggal 26 Meret 2015., melalui : http//www.Nurfadila384.

Umar. K, 2008. Hubungan antara karakteristik dan sikap ibu balita dengan penerapan imunisasi campak di wilayah kerja Puskesmas Gunungpati, Skripsi.

Wawan, A dkk. 2010., Teori \& pengukuran pengetahuan, sikap, dan perilaku manusia, Yogyakarta Nuha Medika

WHO,UNICEF World Bank, 2009. State of the world's vaccines and immunization. 3rd edition. Geneva: World Health Organization. 